\title{
Study on Vibration of Marine Diesel-Electric Hybrid Propulsion System
}

\author{
Nengqi Xiao, ${ }^{1}$ Ruiping Zhou, ${ }^{1}$ Xiang $X u,{ }^{2,3}$ and Xichen Lin ${ }^{1}$ \\ ${ }^{1}$ School of Energy and Power Engineering, Wuhan University of Technology, Wuhan 430063, China \\ ${ }^{2}$ College of Mechanical and Power Engineering, China Three Gorges University, Yichang 443002, China \\ ${ }^{3}$ State Key Laboratory of Automotive Safety and Energy, Tsinghua University, Beijing 100084, China
}

Correspondence should be addressed to Nengqi Xiao; xiaonengqi@126.com

Received 25 May 2016; Revised 29 September 2016; Accepted 11 October 2016

Academic Editor: Dane Quinn

Copyright (C) 2016 Nengqi Xiao et al. This is an open access article distributed under the Creative Commons Attribution License, which permits unrestricted use, distribution, and reproduction in any medium, provided the original work is properly cited.

\begin{abstract}
This study analyzes the characteristics of hybrid propulsion shafting and builds mathematical models and vibration equations of shafting using the lumped parameter method. Main focus is on the asymmetric double diesel propulsion shafting operation process and the impact of the phase angle and motor excitation on torsional vibration of shafting. Model result is validated by testing results conducted on double diesel propulsion shafting bench. Mathematical model and model-building methods of shafting are correct.
\end{abstract}

\section{Introduction}

With the rapid development of shipbuilding technology, marine power plant goes toward large-scale, complexity, and automation development. As the provider of ship power, the ship power plant plays an important role in the economy, maneuverability, safety, and reliability of the ship's operation $[1,2]$. With the introduction of the new standard of ship gas emission and ship vibration noise, the shipping industry has higher requirements for energy saving, emission reduction, and low noise. The vibration of ship propulsion shafting directly affects the performance and safety of the ship [3-5]. At present, the hybrid propulsion shafting is widely used in various types of ships. Comparing with the traditional propulsion shafting, hybrid propulsion shafting has multiple transmission branches of gearbox and multiple elastic coupling and the shaft. Its structure is more complex, and the shafting vibration is also more complex. The ship hybrid propulsion system is mainly composed of three parts, which are mechanical propulsion system, electric propulsion system, and integrated control system.

Ship propulsion shafting torsional vibration is one of the factors that affect the running safety and ship noise and starts to receive extensive attention from the industry. Comparing with the current ship propulsion system, ship propulsion shafting structure is relatively simpler in the early days. Shafting torsional vibration lumped parameter model is usually simplified as straight branched-chain type. Straight branched-chain type vibration model (undamped $[6,7]$ or damped $[8,9]$ ) is usually calculated by Holzer method $[10$, 11]. With the development of shipbuilding technology, the propulsion system of ship power plant is becoming more and more complex, and the lumped parameter model that describes the torsional vibration of the shaft system is in the process of simplification. Torsional vibration model with branching system has been solved with the system matrix eigenvalue extraction method or the trial-and-error search method based on the transfer matrix [12-15]. With the continuous improvement of the finite element software, the finite element method is used to calculate the torsional vibration of the complex ship propulsion shafting $[16,17]$. As the operating conditions of hybrid propulsion system are more complex, the torsional vibration mechanism is more complex. At present, there are few works in literature about the research on the torsional vibration of the hybrid propulsion system in new ship propulsion plant. Hybrid propulsion system has a more complex mathematical model of torsional vibration. The vibration excitation source includes the excitation torque generated by the gas pressure of the diesel engine, by the propeller water power, by the electromagnetic field, and so on. 
TABLE 1: Basic parameters of hybrid propulsion shafting.

\begin{tabular}{lcc}
\hline Component Name & Type & Basic parameter \\
\hline 3-cylinder diesel engine 1\# & TD226B-3C & Power $=40 \mathrm{Kw}$, speed $=1500 \mathrm{r} / \mathrm{min}$, bore $=105 \mathrm{~mm}$, stroke $=120 \mathrm{~mm}$ \\
4-cylinder diesel engine 2\# & TD226B-4C & Power $=60 \mathrm{Kw}$, speed $=1500 \mathrm{r} / \mathrm{min}$, bore $=105 \mathrm{~mm}$, stroke $=120 \mathrm{~mm}$ \\
Flexible coupling & HGTL1.8 & Rated torque $=1.8 \mathrm{kNm}$, maximum torque $=4.5 \mathrm{kNm}$, relative damping $=1.1$ \\
Gearbox & 2GWH100 & $i=1: 1$ \\
Motor shaft & 2YVP200L & Power $=30 \mathrm{Kw}$, frequency $=50 \mathrm{~Hz}$ \\
Eddy current dynamometer & DW250 & Power $=250 \mathrm{~kW}$ \\
\hline
\end{tabular}

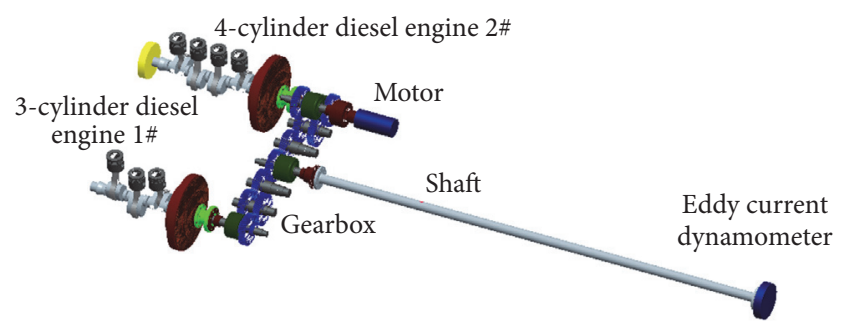

FIGURE 1: Three-dimensional model of hybrid propulsion shafting.

To sum up, this paper will study the characteristics of the hybrid propulsion system and its operating conditions and establish a mathematical model of the torsional vibration of the hybrid propulsion system. Based on the mathematical model of vibration, the free vibration and forced vibration of the system are calculated using system matrix method. Through the research on the vibration mechanism and the excitation torque of the hybrid propulsion system, the paper focuses on the influence of the phase angle of twin-engine parallel operation and the electromagnetic excitation torque on the propulsion shafting. By means of self-developed test system and hybrid propulsion shafting test bench test and analysis, the correctness of the theoretical model and algorithm is verified.

\section{Establishment of Shafting Torsional Vibration Model and Equation}

The hybrid propulsion shafting system is set up as follows: three-cylinder diesel engine and four-cylinder diesel engine are connected to electric eddy current dynamometer through gearbox with transmission branch, the universal joint, and drive shaft. Two diesel engines and the motor are connected to the gearbox via the universal joint. The three-dimensional model of the hybrid propulsion system is shown in Figure 1. The basic parameters of each component of the hybrid propulsion shafting are shown in Table 1.

The hybrid propulsion shafting has several operating conditions as follows:

(1) Single machine condition: 3-cylinder diesel engine or 4-cylinder diesel engine drives either eddy current dynamometer or shaft generator or both of them.
(2) Twin diesel condition: 3-cylinder diesel engine and four-cylinder diesel engine jointly drive either eddy current dynamometer or shaft generator or both of them.

(3) Single diesel hybrid conditions: 3-cylinder diesel engine or 4-cylinder diesel engine are combining with the motor drive eddy current dynamometer.

(4) Twin diesel hybrid conditions: 3-cylinder diesel engine, 4-cylinder diesel engine, and the motor drive eddy current dynamometer.

2.1. Establishment of Shafting Vibration Model. Ship propulsion shafting torsional vibration equivalent system was established by simplified principle and method of equivalent system. Each part of the mathematical model of torsional vibration was modeled separately and then assembled. The hybrid propulsion system can be simplified as a lumped parameter torsional vibration model shown in Figure 2 and the system equivalent parameters are shown in Table 2. The boundary condition of the mathematical model of the torsional vibration of ship propulsion shafting is the six degrees of freedom of the two end points and the end point of the branch in Figure 2. According to the length, diameter, and elastic modulus of the material, the stiffness of shaft can be calculated in (1), but the stiffness of the elastic coupling is generally provided by the manufacturer. The damping of the system can be divided into the external damping produced by the component and the external friction and the hysteresis of the internal torsional deformation of the material in Figure 2. According to the specification, it is mainly to consider the external damping of the diesel engine mass point and propeller mass point as well as the internal damping of the diesel engine crankshaft and the transmission shaft in Table 2. The external damping coefficient of the diesel engine mass point and propeller mass point is 0.0085 and 0.05 in Figure 2. The internal damping coefficients of the diesel engine crankshaft and the drive shaft are 0.01 and 0.0063 in Figure 2. The internal damping coefficient of the flexible coupling is provided by the manufacturer. In this paper, the internal damping coefficient of elastic coupling is 1.13.

$$
k=\frac{\pi}{32} \frac{G}{L}\left(D^{4}-d^{4}\right)
$$

where $k$ is stiffness $(\mathrm{Nm} / \mathrm{rad}) . D$ is external diameter $(\mathrm{m})$. $d$ is internal diameter (m). $L$ is length $(\mathrm{m}) . D$ is external 
TABLE 2: Equivalent parameters of torsional vibration.

\begin{tabular}{|c|c|c|c|}
\hline Number & Inertia $\left(\mathrm{kgm}^{2}\right)$ & Stiffness $(\mathrm{MNm} / \mathrm{rad})$ & Identified \\
\hline 1 & 0.101 & - & \\
\hline 2 & 0.0002 & 1.1 & \\
\hline 3 & 0.123 & 1.1 & Cylinder 1 \\
\hline 4 & 0.123 & 1.1 & Cylinder 2 \\
\hline 5 & 0.123 & 1.1 & Cylinder 3 \\
\hline 6 & 0.123 & 1.734 & Cylinder 4 \\
\hline 7 & 1.1134 & - & Flywheel \\
\hline 8 & 0.1954 & 0.0141 & Coupling \\
\hline 9 & 0.1247 & - & \\
\hline 10 & 0.0062 & 0.6793 & \\
\hline 11 & 0.0398 & - & Clutch \\
\hline 12 & 0.0032 & 2.6209 & Clutch \\
\hline 13 & 0.0448 & - & Gear \\
\hline 14 & 0.0462 & 2.5755 & Gear \\
\hline 15 & 0.0463 & - & Gear \\
\hline 16 & 0.0492 & - & Gear \\
\hline 17 & 0.0448 & 2.6209 & Gear \\
\hline 18 & 0.005 & - & Clutch \\
\hline 19 & 0.0451 & 0.5898 & Clutch \\
\hline 20 & 0.0088 & - & \\
\hline 21 & 0.02 & 0.0336 & Shafting \\
\hline 22 & 0.02 & - & Dynamometer \\
\hline 23 & 0.11 & - & Gear \\
\hline 24 & 0.0492 & - & Gear \\
\hline 25 & 0.0463 & - & Gear \\
\hline 26 & 0.0462 & 2.5755 & Gear \\
\hline 27 & 0.0448 & - & Clutch \\
\hline 28 & 0.0032 & 2.6209 & Clutch \\
\hline 29 & 0.0398 & - & \\
\hline 30 & 0.0062 & 0.6793 & Coupling \\
\hline 31 & 0.1247 & - & \\
\hline 32 & 0.1954 & 0.0141 & Flywheel \\
\hline 33 & 1.1134 & - & Cylinder 3 \\
\hline 34 & 0.123 & 1.734 & Cylinder 2 \\
\hline 35 & 0.123 & 1.1 & Cylinder 1 \\
\hline 36 & 0.123 & 1.1 & \\
\hline 37 & 0.0002 & 1.1 & Gear \\
\hline 38 & 0.0448 & - & Clutch \\
\hline 39 & 0.002 & 2.6209 & Clutch \\
\hline 40 & 0.0408 & - & \\
\hline 41 & 0.0164 & 0.5536 & Motor \\
\hline
\end{tabular}

diameter $(\mathrm{m}) . G$ is shear modulus of materials $\left(\mathrm{N} / \mathrm{m}^{2}\right)$, nodular graphite cast iron $G=6.76659 \times 10^{10}\left(\mathrm{~N} / \mathrm{m}^{2}\right)$, or steel $G=8.14993 \times 10^{10}\left(\mathrm{~N} / \mathrm{m}^{2}\right)$.

2.2. Establishment of Shafting Torsional Vibration Equation. Hybrid propulsion shafting torsional vibration lumped parameter model mainly includes straight branched-chain type parts and branch type parts, as shown in Figures 3 and 4.

For straight branched-chain type parts, differential equation of motion of $k$ mass point can be obtained according to basic vibration theory as follows:

$$
\begin{aligned}
J_{k} \ddot{\phi}_{k} & +C_{k} \dot{\phi}_{k}+C_{k-1, k}\left(\dot{\phi}_{k}-\dot{\phi}_{k-1}\right)+C_{k, k+1}\left(\dot{\phi}_{k}-\dot{\phi}_{k+1}\right) \\
& +K_{k-1, k}\left(\phi_{k}-\phi_{k-1}\right)+K_{k, k+1}\left(\phi_{k}-\phi_{k+1}\right) \\
= & T_{k}(t) .
\end{aligned}
$$

Equation (2) can be converted into

$$
\begin{aligned}
J_{k} \ddot{\phi}_{k} & +\left(C_{k-1, k}+C_{k, k+1}\right) \dot{\phi}_{k}-C_{k-1, k} \dot{\phi}_{k-1}-C_{k, k+1} \dot{\phi}_{k+1} \\
& +\left(K_{k-1, k}+K_{k, k+1}\right) \phi_{k}-K_{k-1, k} \phi_{k-1}-K_{k, k+1} \phi_{k+1} \\
& +C_{k} \dot{\phi}_{k}=T_{k}(t) .
\end{aligned}
$$

For branch type parts, $m+1$ mass point's motion differential equation is as follows:

$$
\begin{aligned}
& J_{m+1} \ddot{\phi}_{m+1}+C_{m, m+1}\left(\dot{\phi}_{m+1}-\dot{\phi}_{m}\right) \\
& \quad+C_{m+1, m+2}\left(\dot{\phi}_{m+1}-\dot{\phi}_{m+2}\right) \\
& \quad+K_{m, m+1}\left(\phi_{m+1}-\phi_{m}\right)+K_{m+1, m+2}\left(\phi_{m+1}-\phi_{m+2}\right) \\
& \quad+C_{m+1} \dot{\phi}_{m+1} C_{m+1, n}\left(\dot{\phi}_{m+1}-\dot{\phi}_{n}\right) \\
& \quad+K_{m+1, n}\left(\phi_{m+1}-\phi_{n}\right)=T_{m+1}(t)
\end{aligned}
$$

Equation (4) can be converted into

$$
\begin{aligned}
J_{m+1} \ddot{\phi}_{m+1}+\left(C_{m, m+1}+C_{m+1, m+2}+C_{m+1, n}\right) \dot{\phi}_{m+1} \\
-C_{m, m+1} \dot{\phi}_{m}-C_{m+1, n} \dot{\phi}_{n}-C_{m+1, m+2} \dot{\phi}_{m+2} \\
\quad+\left(K_{m, m+1}+K_{m+1, m+2}+K_{m+1, n}\right) \phi_{m+1} \\
-K_{m, m+1} \phi_{m}-K_{m+1, m+2} \phi_{m+2}-K_{m+1, n} \phi_{n} \\
+C_{m+1} \dot{\phi}_{m+1}=T_{m+1}(t),
\end{aligned}
$$

where $J_{k}$ is $k$ mass point's inertia $\left(\mathrm{kg} \cdot \mathrm{m}^{2}\right) \cdot C_{k}$ is $k$ mass point's damping coefficient $(\mathrm{N} \cdot \mathrm{m} \cdot \mathrm{s} / \mathrm{rad}) . C_{k, k+1}$ is internal damping coefficient between $K$ mass point and $K+1$ mass point $(\mathrm{N} \cdot \mathrm{m} \cdot \mathrm{s} / \mathrm{rad}) . K_{k, k+1}$ is stiffness between $K$ mass point and $K+1$ mass point $(\mathrm{N} \cdot \mathrm{m} / \mathrm{rad}) . T_{k}(t)$ is quality exciting moment $(\mathrm{N} \cdot \mathrm{m})$ acting on $k$ mass point. $\ddot{\phi}_{k}, \dot{\phi}_{k}$, and $\phi_{k}$ are torsional angular displacement, angular velocity, and angular acceleration of $k$ mass point, respectively.

According to (3) and (5), the differential equation of forced vibration of hybrid propulsion system is derived as follows:

$$
[J]\{\ddot{\phi}\}+[C]\{\dot{\phi}\}+[K]\{\phi\}=\{T(t)\},
$$




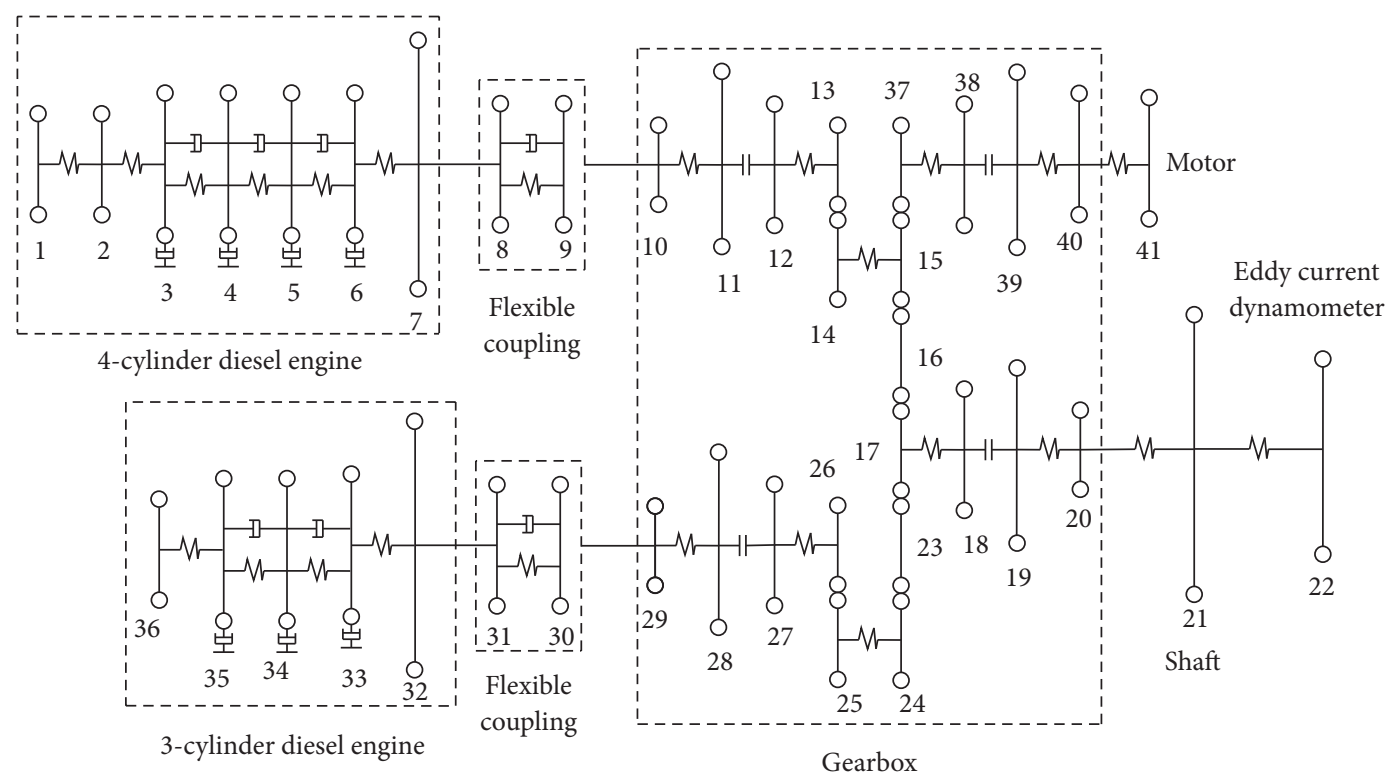

FIGURE 2: Lumped parameter model of hybrid propulsion shafting.

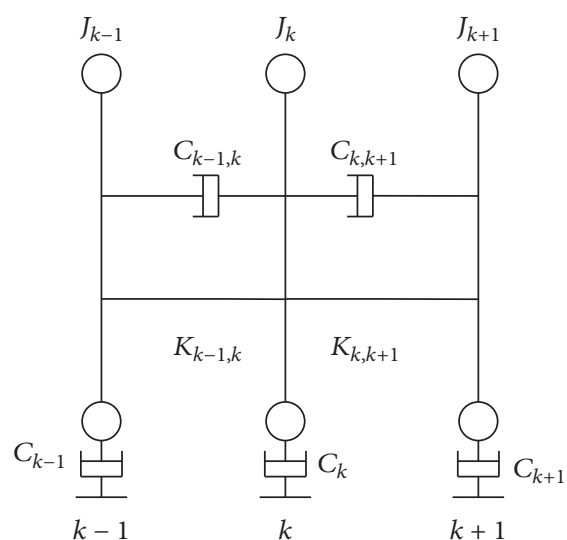

FIGURE 3: Torsional vibration model of straight chain.

TABLE 3: Free vibration natural frequency.

\begin{tabular}{lccccc}
\hline Wn/harmonic & 1 & 2 & 3 & 4 & 5 \\
\hline $\mathrm{r} / \mathrm{min}$ & 834.9 & 1734.1 & 5046.4 & 10478.6 & 17314.0 \\
$\mathrm{~Hz}$ & 13.9 & 28.9 & 84.1 & 174.6 & 288.6 \\
\hline
\end{tabular}

where inertia matrix $[J]$ is diagonal matrix. Stiffness matrix $[K]$ is three-diagonal matrix. Damping matrix $[C]$ is the sum of the internal damping matrix (three-diagonal matrix) and outer damping matrix (diagonal matrix). $\{T(t)\}$ is vector of the excitation torque acting on the system.

According to (6) and the shafting torsional vibration parameters shown in Table 2, the natural frequencies of the free vibration system without damping can be obtained, as shown in Table 3.

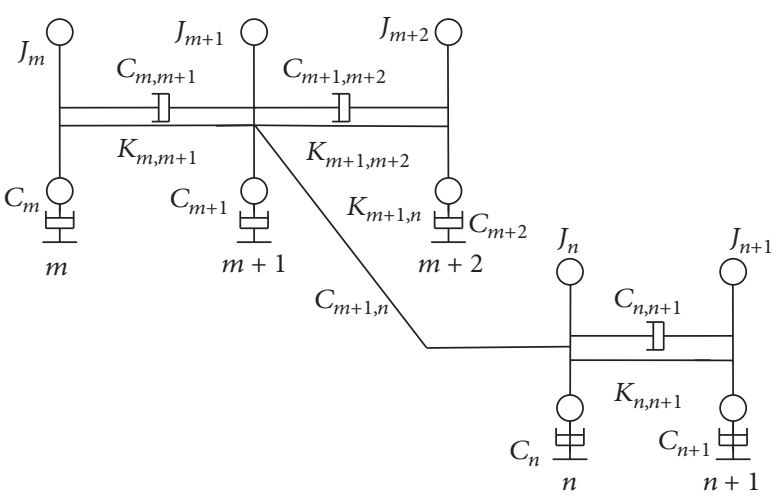

FIGURE 4: Torsional vibration model of branch chain.

\section{Research on Key Technology of Hybrid Propulsion Shafting Torsional Vibration}

3.1. Influence of Phase Angle on Torsional Vibration. With the change of ship sailing condition, the operation mode of hybrid propulsion system will change. The phase angle is not a fixed value in the process of twin-engine parallel operation. Phase angle is the angle between the fuel injection starting points of the first cylinder of each diesel engine. Torque of each cylinder of the diesel engine is a complex harmonic torque consisting of several harmonic moments. Its expression is

$$
M_{k}^{*}=M_{k} e^{i \xi_{k}}
$$

where $M_{k}$ is $k$ mass point's harmonic excitation torque amplitude. $\xi_{k}$ is $k$ mass point's harmonic excitation torque phase.

$$
\xi_{k}=v\left(\xi_{1, k}+\theta\right)
$$




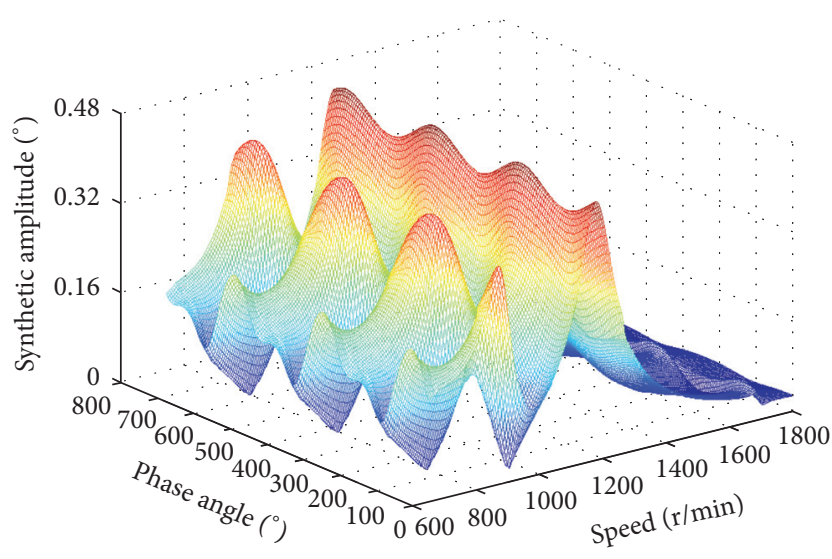

Figure 5: Amplitude of shaft with speed and phase difference.

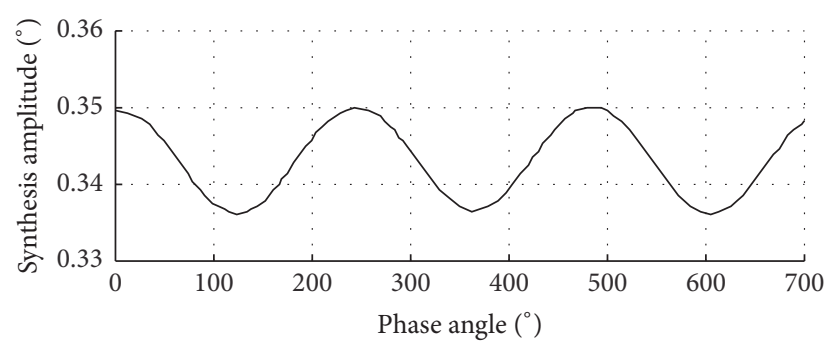

FIGURE 6: $V=1100 \mathrm{r} / \mathrm{min}$ synthesis of amplitude with phase angle.

where $v$ is order. $\xi_{1, k}$ is the firing angle between $i$ cylinder and the first cylinder. $\theta$ is phase angle of twin-engine.

Equations (7) and (8) can be obtained by transformation.

$$
M_{k}^{*}=M_{k} \cos \left[\nu\left(\varsigma_{1, i}+\theta\right)\right]+i \cdot M_{k} \sin \left[v\left(\varsigma_{1, i}+\theta\right)\right] .
$$

Phase angle of twin-engine parallel operation is changed within the range of $0^{\circ}$ to $720^{\circ}$. This paper uses $1^{\circ}$ as interval to calculate middle shaft's synthetic amplitude changing with the speed and phase according to (6) and (9), as shown in Figure 5. Calculation results at $1000 \mathrm{r} / \mathrm{min}$ are shown in Figure 6. Figure 5 shows the relationship between the phase angle of the diesel engine, the speed of the diesel engine, and the amplitude of the torsional vibration of the shaft. When the diesel engine speed is a fixed value, the torsional vibration amplitude of the shaft can be obtained with the change of the phase angle of the diesel engine by Figures 5 and 6 . When the phase angle of two diesel engines is a fixed value, the curve shows the torsional vibration characteristics of the shaft in the range of diesel engine speed.

The calculation results show that synthetic amplitude value periodically fluctuates with changing phase angle under the same speed; thus the phase angle has a certain effect on the calculation results of torsional vibration in twin-engine parallel operation.

3.2. Motor Vibration Mechanism and Motor Excitation Torque. In an ideal state, the air gap magnetic field of the motor is in

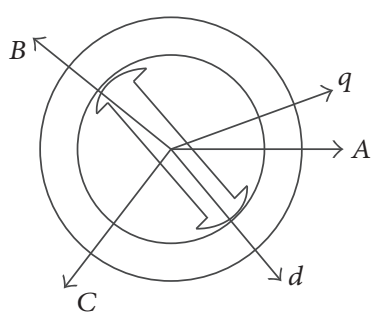

FIGURE 7: Motor physical model.

sinusoidal distribution. Because of the machining error of the motor in the manufacturing process, the magnetic field of the motor must be nonsinusoidal. In order to study the vibration mechanism of the motor and obtain the analytical formula of the electromagnetic torque, the physical model of $A, B$, and $C$ phase motor is established as shown in Figure 7.

According to $A, B$, and $C$ phase flux linkage, the relationship between the fluxes can be set up as shown in the following three phase matrix equations:

$$
\begin{aligned}
\psi_{A B C} & =\left[\begin{array}{l}
\psi_{a}(\theta) \\
\psi_{b}(\theta) \\
\psi_{c}(\theta)
\end{array}\right]=\left[\begin{array}{c}
\psi_{a}(\theta) \\
\psi_{b}\left(\theta-\frac{2 \pi}{3}\right) \\
\psi_{c}\left(\theta+\frac{2 \pi}{3}\right)
\end{array}\right] \\
& =\left[\begin{array}{c}
\sum_{k=1}^{\infty} \psi_{(2 k-1)} \cos [(2 k-1) \theta] \\
\sum_{k=1}^{\infty} \psi_{(2 k-1)} \cos \left[(2 k-1)\left(\theta-\frac{2 \pi}{3}\right)\right] \\
\sum_{k=1}^{\infty} \psi_{(2 k-1)} \cos \left[(2 k-1)\left(\theta+\frac{2 \pi}{3}\right)\right]
\end{array}\right] .
\end{aligned}
$$

Equation (10) can be transformed to $d q 0$ coordinates flux equation through coordinate transformation:

$$
\psi_{d q}=\left[\begin{array}{c}
\sum_{k=1}^{\infty}\left\{\psi_{1}+\left[\psi_{(6 k-1)}+\psi_{(6 k+1)}\right] \cos (6 k \theta)\right\} \\
\sum_{k=1}^{\infty}\left\{\left[-\psi_{(6 k-1)}+\psi_{(6 k+1)}\right] \cos (6 k \theta)\right\} \\
\sum_{k=1}^{\infty} \psi_{(6 k+3)} \cos (6 k+3) \theta
\end{array}\right] .
$$
is

Motor flux produced by fundamental sinusoidal current

$$
\psi_{F}=\left[\begin{array}{ccc}
L_{d} & 0 & 0 \\
0 & L_{q} & 0 \\
0 & 0 & L_{0}
\end{array}\right]\left[\begin{array}{c}
i_{d} \\
i_{q} \\
i_{0}
\end{array}\right],
$$


where $L_{d}, L_{q}$, and $L_{0}$ represent $d, q$, and 0 under $d q 0$ coordinate axis of the stator inductance, respectively. $i_{d}, i_{q}$, and $i_{0}$ represent $d, q$, and 0 under $d q 0$ coordinate axis of the current, respectively.

According to (11) and (12) total flux is

$$
\psi_{\text {toal }}=\left[\begin{array}{ccc}
L_{d} & 0 & 0 \\
0 & L_{q} & 0 \\
0 & 0 & L_{0}
\end{array}\right]\left[\begin{array}{c}
i_{d} \\
i_{q} \\
i_{0}
\end{array}\right]
$$

$$
+\left[\begin{array}{c}
\sum_{k=1}^{\infty}\left\{\psi_{1}+\left[\psi_{(6 k-1)}+\psi_{(6 k+1)}\right] \cos (6 k \theta)\right\} \\
\sum_{k=1}^{\infty}\left\{\left[-\psi_{(6 k-1)}+\psi_{(6 k+1)}\right] \sin (6 k \theta)\right\} \\
\sum_{k=1}^{\infty} \psi_{(6 k+3)} \cos (6 k+3) \theta
\end{array}\right]
$$

Electromotive force can be derived from the total magnetic chain derivative:

$$
E_{d q 0}=\left[\begin{array}{c}
E_{d} \\
E_{q} \\
E_{0}
\end{array}\right]=\left[\begin{array}{c}
-\omega_{r} L_{d} i_{d}-\omega_{r} \sum_{i=1}^{\infty}\left\{\left[(6 k-1) \psi_{(6 k-1)}+(6 k+1) \psi_{(6 k+1)} \sin 6 k \theta\right]\right\} \\
\omega_{r} L_{d} i_{d}+\omega_{r} \sum_{k=1}^{\infty}\left\{\psi_{1}+\left[-(6 k-1) \psi_{(6 k-1)}+(6 k+1) \psi_{(6 k+1)}\right] \cos (6 k \theta)\right\} \\
-\omega_{r} \sum_{k=1}^{\infty}\left[(6 k+3) \psi_{(6 k+3)} \sin (6 k+3) \theta\right]
\end{array}\right]
$$

According to the principle of the motor, the electromagnetic torque is

$$
T_{e}=\frac{1}{\omega_{m}} \cdot \frac{3}{2} E^{T} i_{d q 0}=\frac{p}{\omega_{r}} \cdot \frac{3}{2} E^{T} i_{d q 0}
$$

where $\omega_{m}$ is mechanical angular velocity of the rotor. $\omega_{r}$ is rotor electrical angular velocity.

By (14) and (15), the analytical solution of the electromagnetic torque is

$$
\begin{aligned}
T_{e} & =\frac{3}{2} p\left[\left(L_{d}-L_{q}\right) i_{d} i_{q}+\psi_{1} i_{q}\right]-\frac{3}{2} \\
& \cdot p\left[\sum _ { k = 1 } ^ { \infty } \left\{\left[(6 k-1) \psi_{(6 k-1)}+(6 k+1) \psi_{(6 k+1)}\right]\right.\right. \\
& \left.\cdot \sin (6 k \theta)\} i_{d}\right]+\frac{3}{2} p \sum_{k=1}^{\infty}\left\{\left[-(6 k-1) \psi_{(6 k-1)}\right.\right. \\
& \left.\left.+(6 k+1) \psi_{(6 k+1)}\right] \cos (6 k \theta)\right\} i_{q} .
\end{aligned}
$$

The second and third terms in (16) are $6 k$ order torque caused by the magnetic field harmonic. Therefore, in the process of torsional vibration calculation of the hybrid propulsion shafting, $6 k$ order torque caused by the field harmonic is needed to be considered at the quality point of the motor. According to the torsional vibration model of the hybrid propulsion system as shown in Figure 2, we can know that the second torque and third torque in (16) are the excitation torque at the 41st mass point of the motor.

According to the forced vibration differential equation (4), the amplitude of the twenty-first mass point drive shaft can be calculated under the condition of only considering the motor excitation torque, as shown in Figure 6. In Figure 8, the result of the forced vibration calculation of the

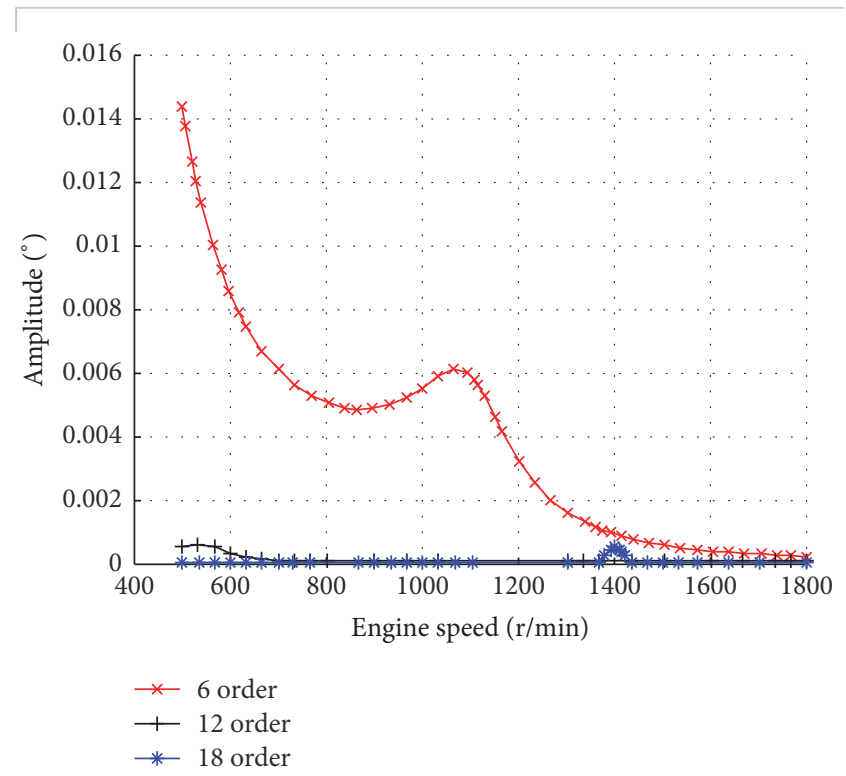

FIGURE 8: The 21st mass (shaft) of amplitude values. Only consider motor excitation.

twenty-first mass point is given. The forced vibration amplitude curve includes 6 harmonic amplitude curve, 12 harmonic amplitude curve, and 18 harmonic amplitude curve.

To sum up, according to the diesel engine exciting force equation (9), motor electromagnetic harmonic exciting force caused by (16) and the forced vibration equation (6) of hybrid propulsion shafting vibration response is calculated. As the phase angle of twin-engine parallel operation changes in the range of 0 degrees to 720 degrees, only the calculation result of the vibration amplitude of the transmission shaft at $\theta=120^{\circ}$ is shown in Figure 9. From Figure 9, we can see that the resonance amplitude of the transmission shaft is 


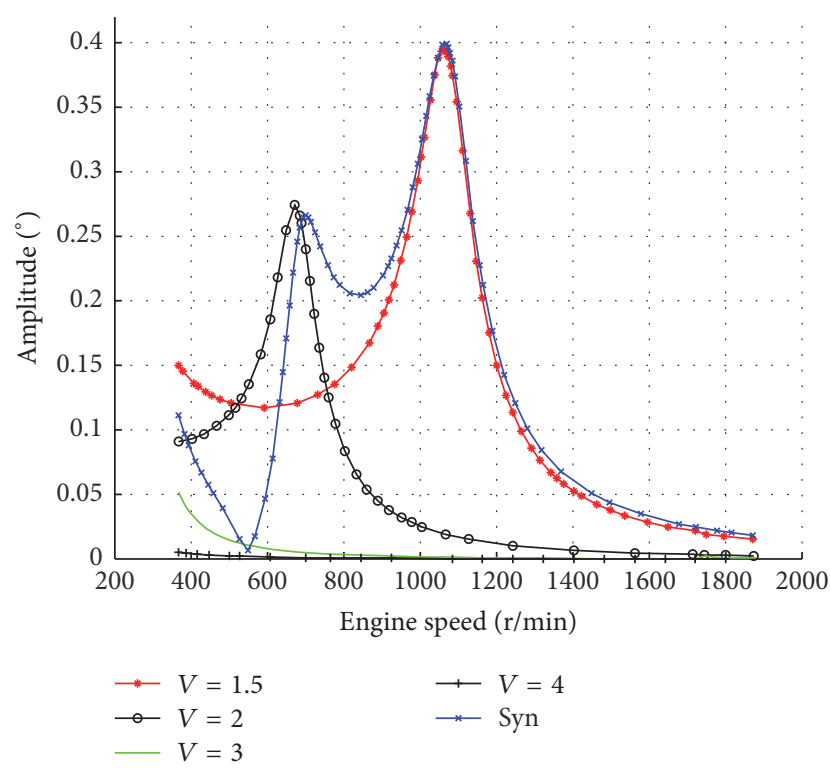

FIGURE 9: The 21st mass (shaft) of amplitude values.

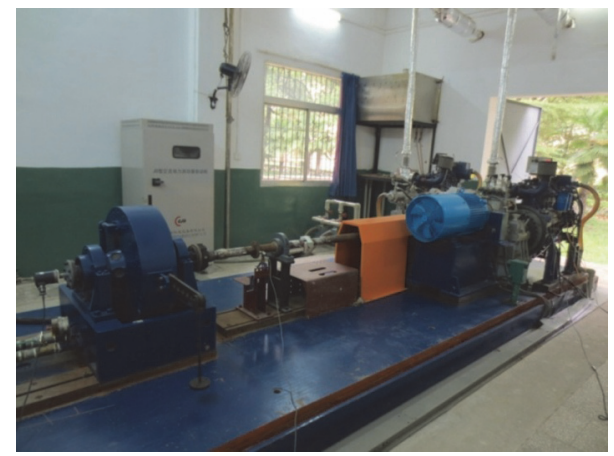

FIGURE 10: Experiment platform of hybrid propulsion shafting.

0.394 degrees when the resonance speed of $V=1.5$ order is $1060 \mathrm{r} / \mathrm{min}$

\section{Test and Analysis of Hybrid Propulsion Shafting}

4.1. Hybrid Propulsion Shafting Experiment Platform. In order to verify the correctness of the calculation result, hybrid propulsion shafting experiment platform is used for torsional vibration measurement and analysis, as shown in Figure 10. The key parameters of hybrid propulsion system experiment platform are listed in Table 1. The gear wheel is installed on the transmission shaft to facilitate the installation of the vibration test fixture, as shown in Figure 11.

This test system uses eddy current sensor. The noncontact electrical measuring method is adopted to improve the shafting torsional vibration testing, as shown in Figure 12.

4.2. Data Analysis. In the experimental bench, the test of torsional vibration of the transmission shaft is carried out in

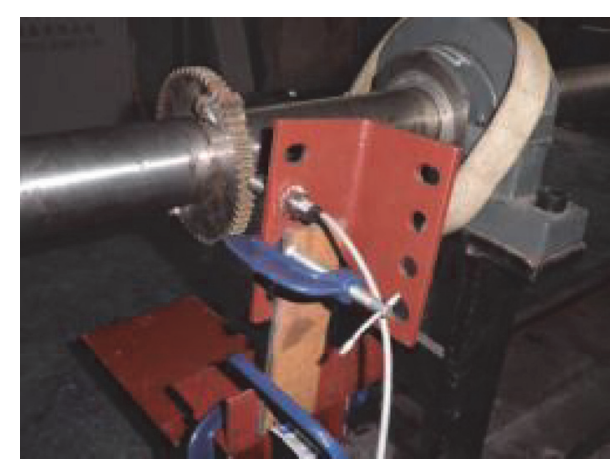

FIGURE 11: Measuring point of hybrid propulsion shafting.

the $800 \mathrm{r} / \mathrm{min}-1500 \mathrm{r} / \mathrm{min}$ range by using the self-developed YDZT-2013 vibration test system. Through the analysis of the data, it is found that the torsional vibration amplitude of the transmission shaft has resonance point in the 1.5 harmonic times, as shown in Figures 13 and 14. We can see that the resonance amplitude of the transmission shaft is 0.4040 degrees when the resonance speed of $V=1.5$ order is $1079.53 \mathrm{r} / \mathrm{min}$.

Comparison and analysis of the data from the test and the theoretical calculation are as below:

(1) The natural frequency of the system can be calculated as $1619.29 \mathrm{r} / \mathrm{min}$ from the test values shown in Figure 13. Comparing with the 2-order natural frequency $1734.1 \mathrm{r} / \mathrm{min}$ shown in Table 3 , the error between the test value and the theoretical value is $6.6 \%$. The theoretical value is basically consistent with the test value.

(2) From the calculation results of Figure 9, the resonance amplitude of the transmission shaft is 0.394 degrees when the resonance speed of $V=1.5$ order is $1060 \mathrm{r} / \mathrm{min}$ in theoretical calculation. The resonance amplitude of the transmission shaft is 0.4040 degrees when the resonance speed of $V=1.5$ order is $1079.53 \mathrm{r} / \mathrm{min}$ in vibration test and analysis, as shown in Figure 13. The error between the test value and the theoretical value is $2.4 \%$. The theoretical value is basically consistent with the test value.

\section{Conclusion}

(1) With the same speed and different phase angle of twin-engine parallel operation, hybrid propulsion system of shafting torsional vibration amplitude changes periodically with the phase angle as shown in Figure 6. The significance of the research is to provide the theoretical basis of the ship's torsional vibration to the design professionals during the design stage of ship propulsion shafting.

(2) Due to the motor's nonsinusoidal magnetic field distribution, $6 k$ order torque caused by electrical harmonic has been analyzed. The general analytical formula of electromagnetic torque excitation force is 


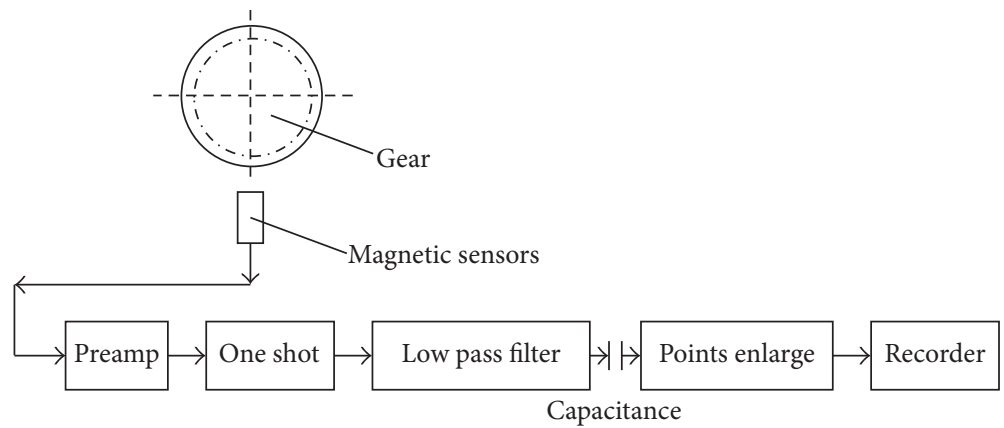

FIGURE 12: Test principles of noncontact measuring method.

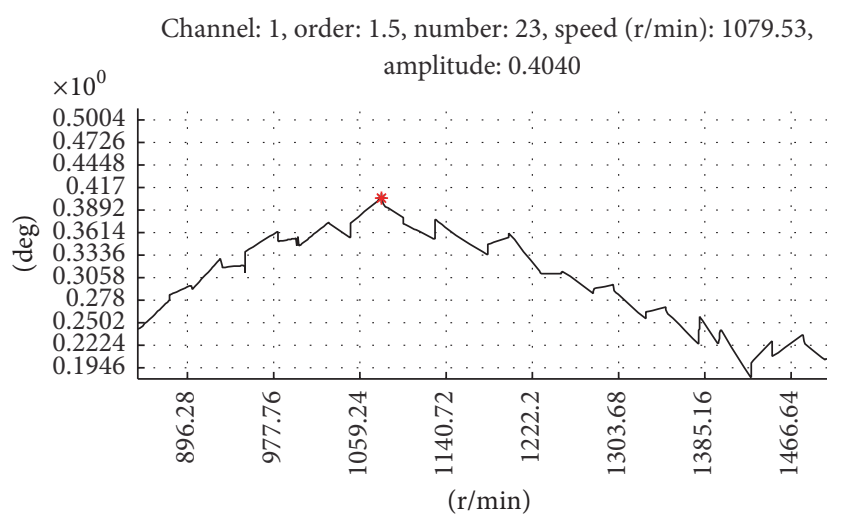

FIGURE 13: $V=1.5$-order amplitude value of the drive shaft.

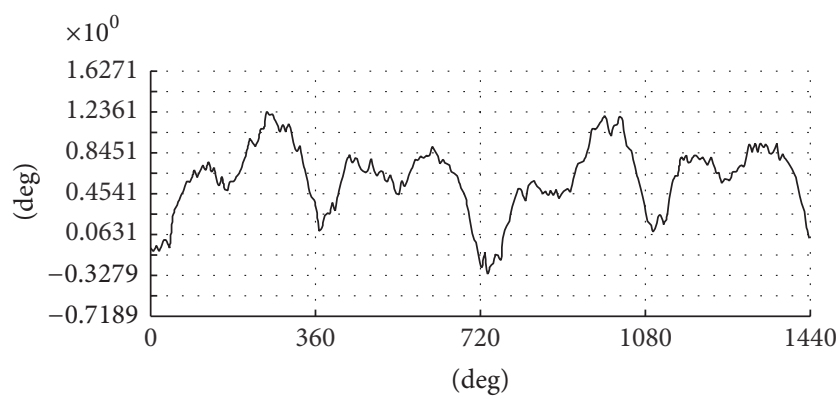

FIGURE 14: Speed $=1079.53 \mathrm{r} / \mathrm{min}$ time domain waveform of drive shaft.

derived. The significance of the research is to lay a theoretical foundation and more accurate theoretical calculation for the forced vibration calculation of the marine hybrid propulsion system.

(3) The hybrid propulsion system is tested using the test bench and the self-developed YDZT-2013 type vibration instrument. The theoretical data and the testing data are compared and analyzed, and the mathematical model and the algorithm are verified.

\section{Competing Interests}

The authors declare that they have no competing interests.

\section{References}

[1] J. Herdzik, "Possibilities of improving safety and reliability of ship propulsion system during dp operations," Journal of KONES, vol. 19, no. 2, pp. 219-226, 2012.

[2] G. de Melo Rodriguez, I. Echevarrieta, and J. M. Serra, "Improving the efficiency of a high speed catamaran through the replacement of the propulsion system," TransNav, the International Journal on Marine Navigation and Safety of Sea Transportation, vol. 9, no. 4, pp. 531-535, 2015.

[3] W. Rzadki and H. S. Horn, "Method and apparatus for operation of a marine vessel hybrid propulsion system," U.S. Patent 8,545,278, 2013.

[4] G. Castles, G. Reed, A. Bendre et al., "Economic benefits of hybrid drive propulsion for naval ships," in Proceedings of the IEEE Electric Ship Technologies Symposium (ESTS '09), pp. 515520, April 2009.

[5] J. Kowalski, W. Leśniewski, and W. Litwin, "Multi-source-supplied parallel hybrid propulsion of the inland passenger ship STA.H. Research work on energy efficiency of a hybrid propulsion system operating in the electric motor drive mode," Polish Maritime Research, vol. 20, no. 3, pp. 20-27, 2013.

[6] A. H. Church, Mechanical Vibrations, John Wiley \& Sons, 1963.

[7] L. Meirovitch, Elements of Vibration Analysis, McGraw-Hill, New York, NY, USA, 1975.

[8] J. C. Snowdon, Vibration and Shock in Damped Mechanical Systems, John Wiley \& Sons, 1968.

[9] D. E. Newland, Mechanical Vibration Analysis and Computation, Courier Corporation, 2006.

[10] J. P. Denhartog and J. P. Li, "Forced torsional vibrations with damping: an extension of Holzer's method," Journal of Applied Mechanics of the ASME, vol. 13, no. 4, pp. A276-A280, 1946.

[11] T. W. Spaetgens, "Holzer method for forced-damped torsional vibrations," Journal of Applied Mechanics-Transactions of the ASME, vol. 17, no. 1, pp. 59-63, 1950.

[12] T. Iwatsubo, S. Arii, and R. Kawai, "Coupled lateral-torsional vibration of rotor system trained by gears-part 1: analysis by transfer matrix method," Bulletin of the JSME, vol. 27, no. 224, pp. 271-277, 1984.

[13] S. Sankar, "On the torsional vibration of branched systems using extended transfer matrix method," Journal of Mechanical Design, vol. 101, no. 4, pp. 546-553, 1979.

[14] Y. Kaneko, T. Momoo, and Y. Okada, “Torsional vibration analysis of blade-disk-shaft system by the finite-element method and the transfer matrix method," Transactions of the Japan Society of Mechanical Engineers C, vol. 61, no. 586, pp. 2210-2215, 1995. 
[15] S.-C. Hsieh, J.-H. Chen, and A.-C. Lee, "A modified transfer matrix method for the coupling lateral and torsional vibrations of symmetric rotor-bearing systems," Journal of Sound \&Vibration, vol. 289, no. 1-2, pp. 294-333, 2006.

[16] Y. Kaneko, T. Momoo, and Y. Okada, “Torsional vibration analysis of blade-disk-shaft system by the finite-element method and the transfer matrix method," Transactions of the Japan Society of Mechanical Engineers C, vol. 61, no. 586, pp. 2210-2215, 1995.

[17] J.-S. Wu and C.-H. Chen, "Torsional vibration analysis of gearbranched systems by finite element method," Journal of Sound \& Vibration, vol. 240, no. 1, pp. 159-182, 2001. 


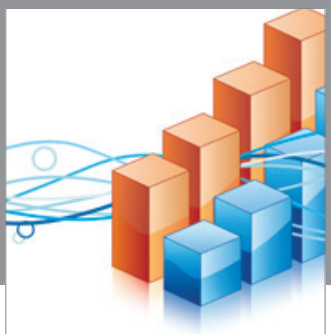

Advances in

Operations Research

vatem alat4

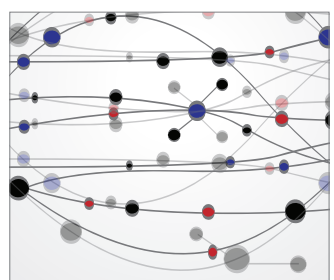

\section{The Scientific} World Journal
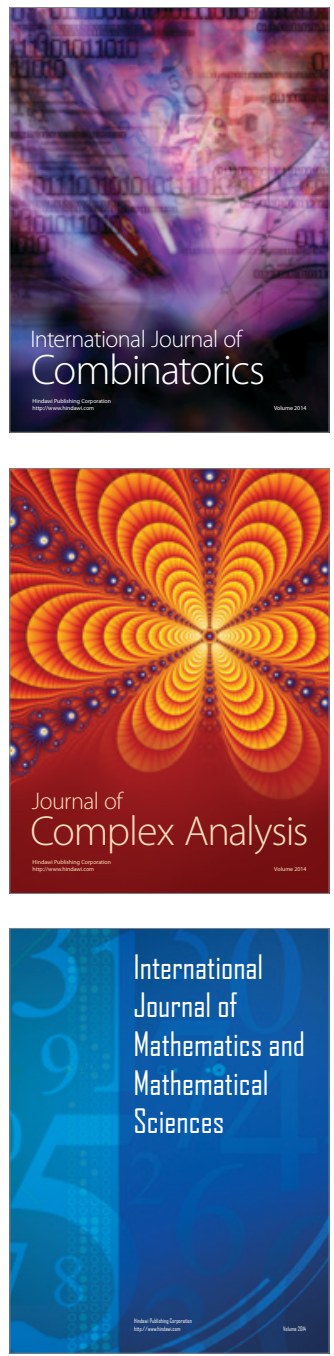
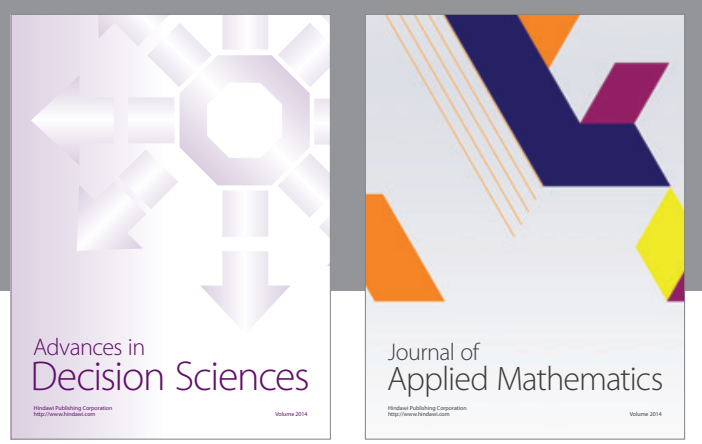

Algebra

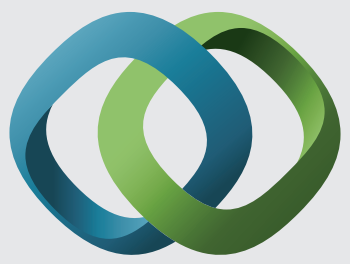

\section{Hindawi}

Submit your manuscripts at

http://www.hindawi.com
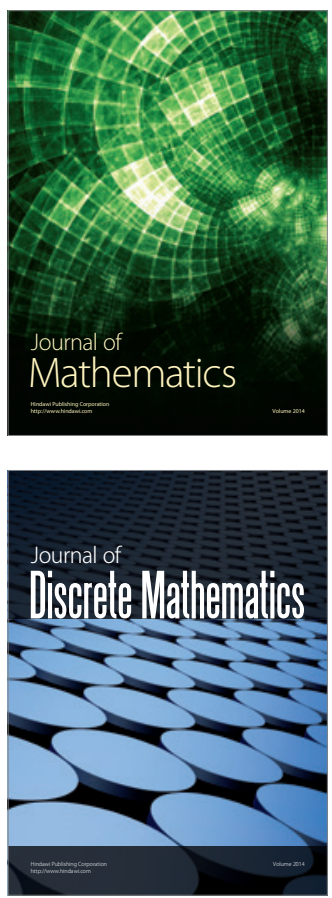

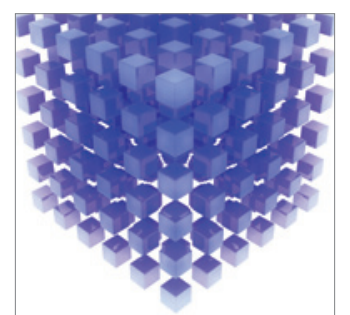

Mathematical Problems in Engineering
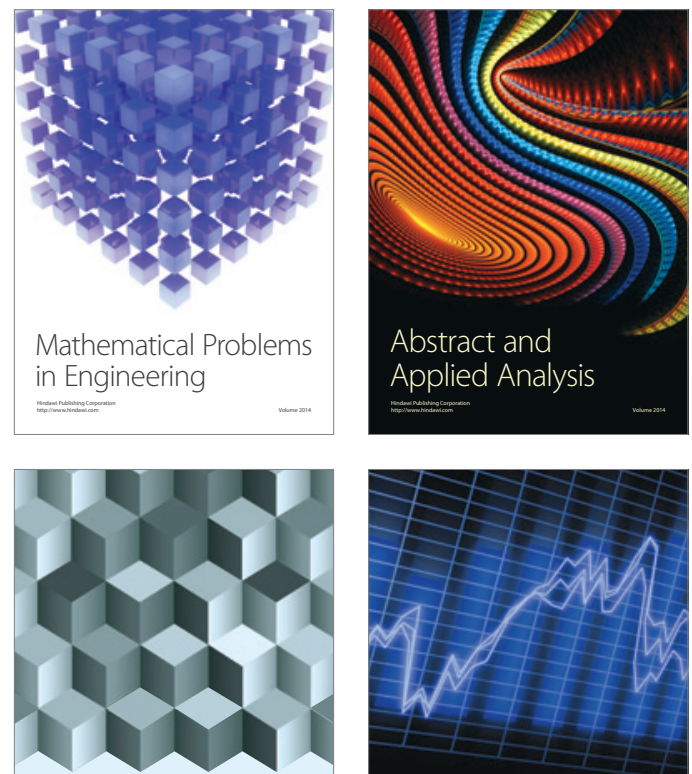

Journal of

Function Spaces

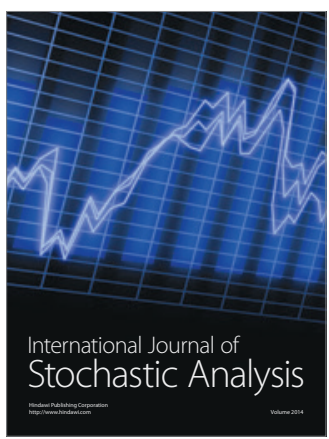

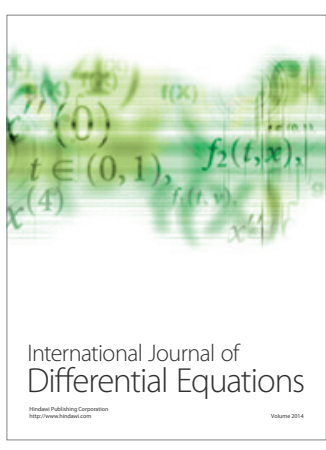
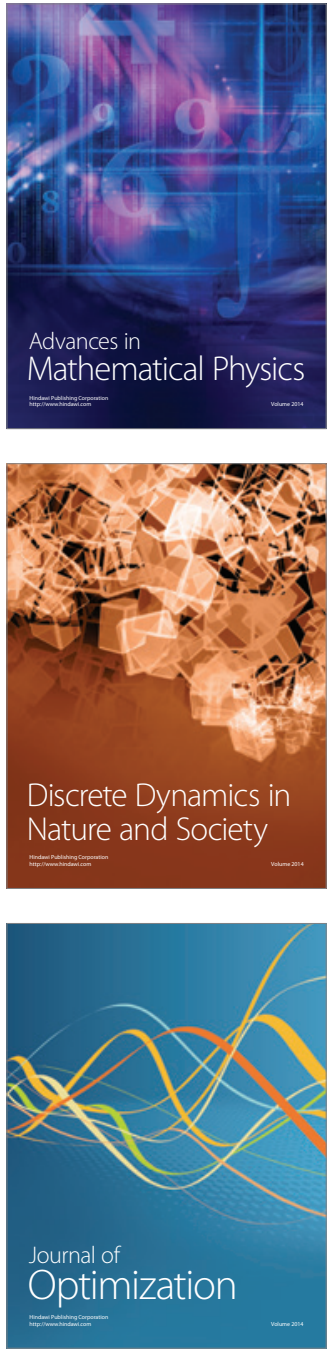